\title{
Once-Daily Sustained-Release Matrix Tablets of Nicorandil: Formulation and In Vitro Evaluation
}

Submitted: September 4, 2003; Accepted: October 20, 2003

K. Raghuram Reddy, ${ }^{1}$ Srinivas Mutalik, ${ }^{1}$ and Srinivas Reddy ${ }^{1}$

${ }^{1}$ College of Pharmaceutical Sciences, Manipal-576119, Karnataka, India

\begin{abstract}
The objective of the present study was to develop once-daily sustained-release matrix tablets of nicorandil, a novel potassium channel opener used in cardiovascular diseases. The tablets were prepared by the wet granulation method. Ethanolic solutions of ethylcellulose (EC), Eudragit RL-100, Eudragit RS-100, and polyvinylpyrrolidone were used as granulating agents along with hydrophilic matrix materials like hydroxypropyl methylcellulose (HPMC), sodium carboxymethylcellulose, and sodium alginate. The granules were evaluated for angle of repose, bulk density, compressibility index, total porosity, and drug content. The tablets were subjected to thickness, diameter, weight variation test, drug content, hardness, friability, and in vitro release studies. The granules showed satisfactory flow properties, compressibility, and drug content. All the tablet formulations showed acceptable pharmacotechnical properties and complied with in-house specifications for tested parameters. According to the theoretical release profile calculation, a oncedaily sustained-release formulation should release $5.92 \mathrm{mg}$ of nicorandil in 1 hour, like conventional tablets, and 3.21 mg per hour up to 24 hours. The results of dissolution studies indicated that formulation F-I (drug-to-HPMC, 1:4; ethanol as granulating agent) could extend the drug release up to 24 hours. In the further formulation development process, F-IX (drug-to-HPMC, 1:4; EC 4\% wt/vol as granulating agent), the most successful formulation of the study, exhibited satisfactory drug release in the initial hours, and the total release pattern was very close to the theoretical release profile. All the formulations (except F-IX) exhibited diffusion-dominated drug release. The mechanism of drug release from F-IX was diffusion coupled with erosion.
\end{abstract}

Corresponding Author: Srinivas Reddy, College of Pharmaceutical Sciences, Manipal-576119,

Karnataka, India; Tel: +91 820-2571201, extension

22482; Fax:+91 820-2571998;

Email: ms.reddy@cops.manipal.edu
KEYWORDS: nicorandil, hydroxypropyl methylcellulose, ethylcellulose, sustained release, matrix tablets

\section{INTRODUCTION}

Hypertension and angina pectoris, the most common cardiovascular diseases, require constant monitoring. Potassium channel openers are presently considered an important class of drugs for hypertension and angina pectoris. The first therapeutic drug shown to possess an ability to hyperpolarize smooth muscle cell membranes is nicorandil, a potent coronary vasodilator. ${ }^{1}$ Although nicorandil is one of the emerging molecules in the case of hypertension and angina, successful treatment means maintenance of blood pressure at a normal physiological level, for which a constant and uniform supply of drug is desired., ${ }^{2,3}$ Nicorandil has a short half-life, and the usual oral dosage regimen is 5 to $40 \mathrm{mg}$ taken 2 to 4 times a day. To reduce the frequency of administration and to improve patient compliance, a once-daily sustained-release formulation of nicorandil is desirable. The drug is freely soluble in water, and hence judicious selection of release-retarding excipients is necessary to achieve a constant in vivo input rate of the drug. The most commonly used method of modulating the drug release is to include it in a matrix system. Because of their flexibility, hydrophilic polymer matrix systems are widely used in oral controlled drug delivery to obtain a desirable drug release profile, costeffectiveness, and broad regulatory acceptance. ${ }^{4}$ Hence, in the present work, an attempt has been made to develop once-daily sustained-release matrix tablets of nicorandil using putative hydrophilic matrix materials such as hydroxypropyl methylcellulose (HPMC), sodium carboxymethylcellulose (CMC), and sodium alginate. The drug release for extended duration, particularly for highly watersoluble drugs, using a hydrophilic matrix system is restricted because of rapid diffusion of the dissolved drug through the hydrophilic gel network. For such drugs with high water solubility, hydrophobic polymers are suitable, along with a hydrophilic matrix for developing sustained-release dosage forms. Hydrophobic polymers provide several advantages, ranging from good stability at varying $\mathrm{pH}$ values and moisture levels to well-established safe applications. Therefore, 
AAPS PharmSciTech 2003; 4 (4) Article 61 (http://www.aapspharmscitech.org).

Table 1. Tablet Formulations*

\begin{tabular}{|c|c|c|c|c|c|c|c|c|c|c|}
\hline SI No & Ingredients (per tablet) & F-I & F-II & F-III & F-IV & F-V & F-VI & F-VII & F-VIII & F-IX \\
\hline 1 & Nicorandil (mg) & 80 & 80 & 80 & 80 & 80 & 80 & 80 & 80 & 80 \\
\hline 2 & Hydroxypropyl methylcellulose (mg) & 320 & - & - & 320 & 320 & 320 & 320 & 320 & 320 \\
\hline 3 & Carboxymethylcellulose (mg) & - & 320 & - & - & - & - & - & - & - \\
\hline 4 & Sodium alginate (mg) & - & - & 320 & - & - & - & - & - & - \\
\hline 5 & Ethanol $(95 \%)$ & qs & qs & qs & - & - & - & - & - & - \\
\hline 6 & Polyvinylpyrrolidone ( $10 \% \mathrm{wt} / \mathrm{vol})$ & - & - & - & $\begin{array}{l}\text { qs } \\
(20 \mathrm{mg})\end{array}$ & - & - & - & - & - \\
\hline 7 & Eudragit RL 100 (10\% wt/vol) & - & - & - & - & $\begin{array}{l}\text { qs } \\
(20 \mathrm{mg})\end{array}$ & - & - & - & - \\
\hline 8 & Eudragit RS $100(4 \% \mathrm{wt} / \mathrm{vol})$ & - & - & - & - & - & $\begin{array}{l}\text { qs } \\
(8 \mathrm{mg})\end{array}$ & - & - & - \\
\hline 9 & Ethylcellulose (2\% wt/vol) & - & - & - & - & - & - & $\begin{array}{l}\text { qs } \\
(4 \mathrm{mg})\end{array}$ & - & - \\
\hline 10 & Eudragit RS $100(8 \% \mathrm{wt} / \mathrm{vol})$ & - & - & - & - & - & - & - & $\begin{array}{l}\text { qs } \\
(16 \mathrm{mg})\end{array}$ & - \\
\hline 11 & Ethylcellulose ( $4 \% \mathrm{wt} / \mathrm{vol})$ & - & - & - & - & - & - & - & - & $\begin{array}{l}\text { qs } \\
(8 \mathrm{mg})\end{array}$ \\
\hline 12 & Magnesium stearate $(\% \mathrm{wt} / \mathrm{wt})$ & 2 & 2 & 2 & 2 & 2 & 2 & 2 & 2 & 2 \\
\hline 13 & Talc $(\% \mathrm{wt} / \mathrm{wt})$ & 2 & 2 & 2 & 2 & 2 & 2 & 2 & 2 & 2 \\
\hline
\end{tabular}

*qs indicates quantity sufficient.

in this study, the hydrophilic polymer was used as matrix material, and the solutions of polymers like ethylcellulose (EC), Eudragit RL-100 (ERL), and Eudragit RS-100 (ERS), and a hydrophilic polymer, polyvinylpyrrolidone (PVP), were used as granulating agents. The objectives of the study were (1) to investigate the performance of several hydrophilic matrix systems prepared by HPMC, CMC, and sodium alginate in controlling the release of this freely soluble drug, and (2) to investigate the effect of granulating agents such as ethanolic solutions of EC, ERL, ERS, and PVP on the release rate of nicorandil.

\section{MATERIALS AND METHODS}

\section{Materials}

HPMC (K4M), CMC (high viscosity), and sodium alginate (high viscosity) were purchased from $\mathrm{BDH}$ Chemicals (Mumbai, India). Ethylcellulose (14 cps) was purchased from SD Fine Chemicals Ltd (Mumbai India). PVP (K30) was procured from Loba Chemie (Mumbai, India). ERL and ERS were procured from Rohm Pharma (Weiterstadt, Germany). Nicorandil was a gift from Wokhardt Pharmaceuticals (Mumbai, India). All the other chemicals used were of high analytical grade.

\section{Methods}

Preparation of Tablets

Different tablet formulations were prepared by wet granulation technique (Formulations I-IX, Table 1). All the powders were passed through ASTM (American Society of Testing and Materials) 80 mesh. Required quantities of drug and polymer were mixed thoroughly, and a sufficient volume of granulating agent (ethanolic solution of EC, ERL, ERS, PVP) was added slowly. After enough cohesiveness was obtained, the mass was sieved through $22 / 44$ mesh. The granules were dried at $40^{\circ} \mathrm{C}$ for 12 hours and thereafter kept in a desiccator for 12 hours at room temperature. Once dry, the granules retained on 44 mesh were mixed with $15 \%$ of fines (granules that passed through 44 mesh). Talc and magnesium stearate were finally added as glidant and lubricant. The practical weight of tablets was calculated based on the drug content of the granulations, and the tablets were compressed (11.8 $\mathrm{mm}$ diameter, biconvex punches) using a single-punch tablet compression machine (Cadmach, Ahmedabad, India). Each tablet contained $80 \mathrm{mg}$ of nicorandil and other pharmaceutical ingredients as listed in Table 1. Prior to the compression, the granules were evaluated for several tests. 


\section{AAPS PharmSciTech 2003; 4 (4) Article 61 (http://www.aapspharmscitech.org).}

\section{Evaluation of Granules}

Angle of Repose

The angle of repose of granules was determined by the funnel method. The accurately weighed granules were taken in a funnel. The height of the funnel was adjusted in such a way that the tip of the funnel just touched the apex of the heap of the granules. The granules were allowed to flow through the funnel freely onto the surface. The diameter of the powder cone was measured and angle of repose was calculated using the following equation ${ }^{5}$ :

$$
\tan \theta=h / r
$$

where $h$ and $r$ are the height and radius of the powder cone.

\section{Bulk Density}

Both loose bulk density (LBD) and tapped bulk density (TBD) were determined. A quantity of $2 \mathrm{~g}$ of powder from each formula, previously lightly shaken to break any agglomerates formed, was introduced into a $10-\mathrm{mL}$ measuring cylinder. After the initial volume was observed, the cylinder was allowed to fall under its own weight onto a hard surface from the height of $2.5 \mathrm{~cm}$ at 2-second intervals. The tapping was continued until no further change in volume was noted. LBD and TBD were calculated using the following formulas ${ }^{6}$ :

$$
\begin{gathered}
\mathrm{LBD}=\text { weight } \text { of the powder/volume of the packing } \\
\begin{array}{c}
\mathrm{TBD}=\text { weight } \text { of the powder/tapped volume of the } \\
\text { packing }
\end{array}
\end{gathered}
$$

\section{Compressibility Index}

The compressibility index of the granules was determined by Carr's compressibility index?

$$
\text { Carr's index }(\%)=[(\mathrm{TBD}-\mathrm{LBD}) \times 100] / \mathrm{TBD}
$$

\section{Total Porosity}

Total porosity was determined by measuring the volume occupied by a selected weight of a powder $\left(\mathrm{V}_{\text {bulk }}\right)$ and the true volume of granules (the space occupied by the powder exclusive of spaces greater than the intermolecular space, $\mathrm{V})^{8}$ :

$$
\text { Porosity }(\%)=\mathrm{V}_{\text {bulk }}-\mathrm{V} / \mathrm{V}_{\text {bulk }} \times 100
$$

\section{Drug Content}

An accurately weighed amount of powdered nicorandil granules $(100 \mathrm{mg})$ was extracted with water and the solution was filtered through $0.45-\mu$ membrane (Nunc, New Delhi, India ). The absorbance was measured at $262 \mathrm{~nm}$ after suitable dilution.

\section{Evaluation of Tablets}

Thickness

The thickness of the tablets was determined using a thickness gauge (Mitutoyo, New Delhi, India). Five tablets from each batch were used, and average values were calculated.

\section{Weight Variation Test}

To study weight variation, 20 tablets of each formulation were weighed using an electronic balance (Denver APX100, Arvada, Colorado), and the test was performed according to the official method. ${ }^{9}$

\section{Drug Content}

Five tablets were weighed individually, and the drug was extracted in water. The drug content was determined as described above.

\section{Hardness and Friability}

For each formulation, the hardness and friability of 6 tablets were determined using the Monsanto hardness tester (Cadmach, Ahmedabad, India) and the Roche friabilator (Campbell Electronics, Mumbai, India), respectively.

\section{Determination of Viscosity}

Viscosity of the aqueous polymeric solution ( $2 \% \mathrm{wt} / \mathrm{vol})$ was determined using the Brookefield viscometer (Brookefield Engineering Laboratories, Stoughton, MA).

\section{In Vitro Release Studies}

The in vitro dissolution studies were carried out using USP apparatus type II (Tab-Machines, Mumbai, India) at $75 \mathrm{rpm}$. The dissolution medium consisted of $0.1 \mathrm{~N}$ hydrochloric acid for the first 2 hours and the phosphate buffer $\mathrm{pH} 7.4$ from 3 to 24 hours $(900 \mathrm{~mL})$, maintained at $37^{\circ} \mathrm{C} \pm 0.5^{\circ} \mathrm{C}$. The drug release at different time intervals was measured by diode array UV-visible spectrophotometer (Hewlett-Packard, Agilent Technologies, New Delhi, India) at $262 \mathrm{~nm}$ using 


\section{AAPS PharmSciTech 2003; 4 (4) Article 61 (http://www.aapspharmscitech.org).}

Table 2. Properties of the Granulations*

\begin{tabular}{lcccccc}
\hline Tablets & $\begin{array}{c}\text { Angle of Re- } \\
\text { pose }\end{array}$ & $\begin{array}{c}\text { Loose Bulk } \\
\text { Density } \\
(\mathbf{g} / \mathbf{m L})\end{array}$ & $\begin{array}{c}\text { Tapped Bulk } \\
\text { Density } \\
(\mathbf{g} / \mathbf{m L})\end{array}$ & $\begin{array}{c}\text { Compressibility } \\
\text { Index (\%) }\end{array}$ & $\begin{array}{c}\text { Total Porosity } \\
\mathbf{( \% )}\end{array}$ & $\begin{array}{c}\text { Drug Content } \\
(\mathbf{\%})\end{array}$ \\
\hline F-I & $24.50 \pm 0.02$ & $0.506 \pm 0.02$ & $0.582 \pm 0.04$ & $13.08 \pm 0.02$ & $27.43 \pm 0.03$ & $98.55 \pm 0.03$ \\
F-II & $21.20 \pm 0.02$ & $0.493 \pm 0.03$ & $0.555 \pm 0.03$ & $11.25 \pm 0.03$ & $26.97 \pm 0.02$ & $95.53 \pm 0.04$ \\
F-III & $22.10 \pm 0.01$ & $0.512 \pm 0.04$ & $0.581 \pm 0.02$ & $11.82 \pm 0.03$ & $26.92 \pm 0.03$ & $96.51 \pm 0.03$ \\
F-IV & $29.85 \pm 0.02$ & $0.289 \pm 0.03$ & $0.335 \pm 0.04$ & $13.75 \pm 0.02$ & $37.03 \pm 0.03$ & $97.54 \pm 0.02$ \\
F-V & $24.11 \pm 0.03$ & $0.283 \pm 0.03$ & $0.325 \pm 0.06$ & $12.95 \pm 0.03$ & $37.61 \pm 0.04$ & $96.79 \pm 0.04$ \\
F-VI & $23.95 \pm 0.01$ & $0.304 \pm 0.02$ & $0.349 \pm 0.02$ & $12.92 \pm 0.04$ & $34.27 \pm 0.02$ & $98.55 \pm 0.02$ \\
F-VII & $22.68 \pm 0.03$ & $0.289 \pm 0.04$ & $0.335 \pm 0.03$ & $13.45 \pm 0.04$ & $37.03 \pm 0.04$ & $97.62 \pm 0.04$ \\
F-VIII & $23.42 \pm 0.02$ & $0.306 \pm 0.04$ & $0.352 \pm 0.02$ & $13.08 \pm 0.03$ & $31.25 \pm 0.03$ & $95.60 \pm 0.03$ \\
F-IX & $24.52 \pm 0.04$ & $0.304 \pm 0.03$ & $0.349 \pm 0.04$ & $12.92 \pm 0.02$ & $31.96 \pm 0.02$ & $97.96 \pm 0.02$ \\
\hline
\end{tabular}

*All values are expressed as mean $\pm \mathrm{SE}, \mathrm{n}=5$.

Chemstation software (Agilent Technologies, New Delhi, India). It was made clear that none of the ingredients used in the matrix formulations interfered with the assay. The release studies were conducted in triplicate (6 tablets in each set), and the mean values were plotted versus time with SDs of less than 3 , indicating the reproducibility of the results.

\section{Calculation of Theoretical Release Profile of Nicorandil from Sustained-Release Formulations}

The total dose of nicorandil for a once-daily sustainedrelease formulation was calculated by the following equation ${ }^{10}$ using available pharmacokinetic data ${ }^{11,12}$ :

$$
\mathrm{D}_{\mathrm{t}}=\text { Dose }\left(1+0.693 \times \mathrm{t} / \mathrm{t}_{1 / 2}\right)
$$

where, $D_{t}=$ total dose of drug; Dose $=$ dose of the immediate release part $(5.92 \mathrm{mg}) ; \mathrm{t}=$ time (hours) during which the sustained release is desired ( 24 hours); $t_{1 / 2}=$ half-life of the drug (1.33 hours).

$$
\mathrm{D}_{\mathrm{t}}=5.92(1+(0.693 \times 24) / 1.33) \cong 80.0 \mathrm{mg}
$$

Hence, the formulation should release $5.92 \mathrm{mg}$ in 1 hour like conventional tablets, and $3.21 \mathrm{mg}$ per hour up to 24 hours thereafter.

\section{RESULTS}

The granules of different formulations were evaluated for angle of repose, LBD, TBD, compressibility index, total porosity, and drug content (Table 2). The results of angle of repose and compressibility index (\%) ranged from $21.20 \pm$ 0.02 to $29.85 \pm 0.02$, and $11.25 \pm 0.03$ to $13.75 \pm 0.02$, respectively. The results of LBD and TBD ranged from 0.283 \pm 0.03 to $0.512 \pm 0.04$ and $0.325 \pm 0.06$ to $0.582 \pm 0.04$, respectively. The bulk density of granules prepared by using only ethanol as the granulating agent was found to be much higher than that of other granules. The results of percentage porosity of the granules ranged from $26.92 \pm 0.03$ to $37.61 \pm$ 0.04. The drug content in a weighed amount of granules of all formulations ranged from $95.53 \pm 0.04$ to $98.55 \pm 0.03 \%$.

The thickness of the tablets ranged from $3.34 \pm 0.03$ to 3.45 $\pm 0.04 \mathrm{~mm}$. The average percentage deviation of 20 tablets of each formula was less than $\pm 5 \%$. Drug content was found to be uniform among different batches of the tablets and ranged from $95.60 \pm 0.02$ to $99.55 \pm 0.15$. The hardness and percentage friability of the tablets of all batches ranged from $4.0 \pm 0.14$ to $4.9 \pm 0.23 \mathrm{~kg} / \mathrm{cm}^{2}$ and $0.65 \pm 0.06$ to $0.88 \pm$ $0.05 \%$, respectively (Table 3 ).

The results of dissolution studies of formulations F-I, F-II, and F-III, composed of HPMC, CMC, and sodium alginate, respectively (drug-to-polymer ratio, 1:4), and prepared using ethanol alone as granulating agent, are shown in Figure 1. Tablets F-I, F-II, and F-III released $32.55 \%, 48.75 \%$, and $62.55 \%$ of nicorandil at the end of 2 hours; and $84.53 \%$, $100 \%$, and $100 \%$ of drug at the end of 12 hours, 8 hours, and 6 hours, respectively. The formulation F-I was further modified by incorporating different granulating agents, such as PVP (10\% wt/vol, F-IV), ERL (10\% wt/vol, F-V), ERS ( $4 \% \mathrm{wt} / \mathrm{vol}, \mathrm{F}-\mathrm{VI})$, and EC ( $2 \% \mathrm{wt} / \mathrm{vol}, \mathrm{F}-\mathrm{VII})$. The results of dissolution studies of these tablets (Figure 2) indicate that F-IV, F-V, F-VI, and F-VII released $30.46 \%, 26.13 \%$, $23.63 \%$, and $20.15 \%$ of nicorandil at the end of 2 hours and $99.50 \%, 99.36 \%, 98.92 \%$, and $97.61 \%$ at the end of 24 hours, respectively. Incorporation of EC (4\% wt/vol, granulating agent) along with HPMC (drug-to-HPMC, 1:4) better retarded the release rate of nicorandil compared to other granulating agents. The in vitro release results of F-VIII (ERS, 8\% wt/vol) and F-IX (EC, 4\% wt/vol) are shown in Figure 3. The tablets F-VIII and F-IX released $22.54 \%$ and $15.35 \%$ of the drug at the end of 2 hours, respectively. From 
AAPS PharmSciTech 2003; 4 (4) Article 61 (http://www.aapspharmscitech.org).

Table 3. Properties of the Compressed Tablets

\begin{tabular}{|c|c|c|c|c|c|}
\hline Tablets & $\begin{array}{c}\text { Thickness" } \\
\text { (mm) }\end{array}$ & $\begin{array}{l}\text { Deviation in Weight } \\
\text { Variation Test }^{\dagger}(\%)\end{array}$ & $\begin{array}{c}\text { Drug Content } \\
(\%)\end{array}$ & $\begin{array}{c}\text { Hardness } \\
\left(\mathbf{k g} / \mathrm{cm}^{2}\right)\end{array}$ & $\begin{array}{c}\text { Friability } \\
(\%)\end{array}$ \\
\hline F-I & $3.42 \pm 0.03$ & $3.895 \pm 0.03$ & $95.60 \pm 0.02$ & $4.5 \pm 0.20$ & $0.75 \pm 0.02$ \\
\hline F-II & $3.45 \pm 0.04$ & $2.876 \pm 0.04$ & $97.96 \pm 0.03$ & $4.0 \pm 0.14$ & $0.88 \pm 0.05$ \\
\hline F-III & $3.39 \pm 0.02$ & $2.987 \pm 0.03$ & $98.37 \pm 0.02$ & $4.0 \pm 0.23$ & $0.85 \pm 0.06$ \\
\hline F-IV & $3.36 \pm 0.03$ & $2.167 \pm 0.01$ & $96.92 \pm 0.02$ & $4.5 \pm 0.25$ & $0.76 \pm 0.03$ \\
\hline $\mathrm{F}-\mathrm{V}$ & $3.45 \pm 0.02$ & $2.567 \pm 0.03$ & $98.55 \pm 0.13$ & $4.6 \pm 0.16$ & $0.72 \pm 0.05$ \\
\hline F-VI & $3.38 \pm 0.03$ & $3.125 \pm 0.02$ & $96.51 \pm 0.03$ & $4.6 \pm 0.16$ & $0.73 \pm 0.04$ \\
\hline F-VII & $3.45 \pm 0.01$ & $2.987 \pm 0.04$ & $97.50 \pm 0.04$ & $4.8 \pm 0.24$ & $0.68 \pm 0.12$ \\
\hline F-VIII & $3.38 \pm 0.02$ & $2.541 \pm 0.02$ & $96.79 \pm 0.02$ & $4.5 \pm 0.19$ & $0.75 \pm 0.06$ \\
\hline F-IX & $3.34 \pm 0.03$ & $2.689 \pm 0.03$ & $99.55 \pm 0.15$ & $4.9 \pm 0.23$ & $0.65 \pm 0.06$ \\
\hline
\end{tabular}

3 to 24 hours, the tablets slowly released the drug, and at the end of 24 hours, the drug release was $95.58 \%$ and $94.68 \%$ from F-VIII and F-IX, respectively. Among all the formulations, formulation F-IX showed the least deviation from the theoretical release pattern.

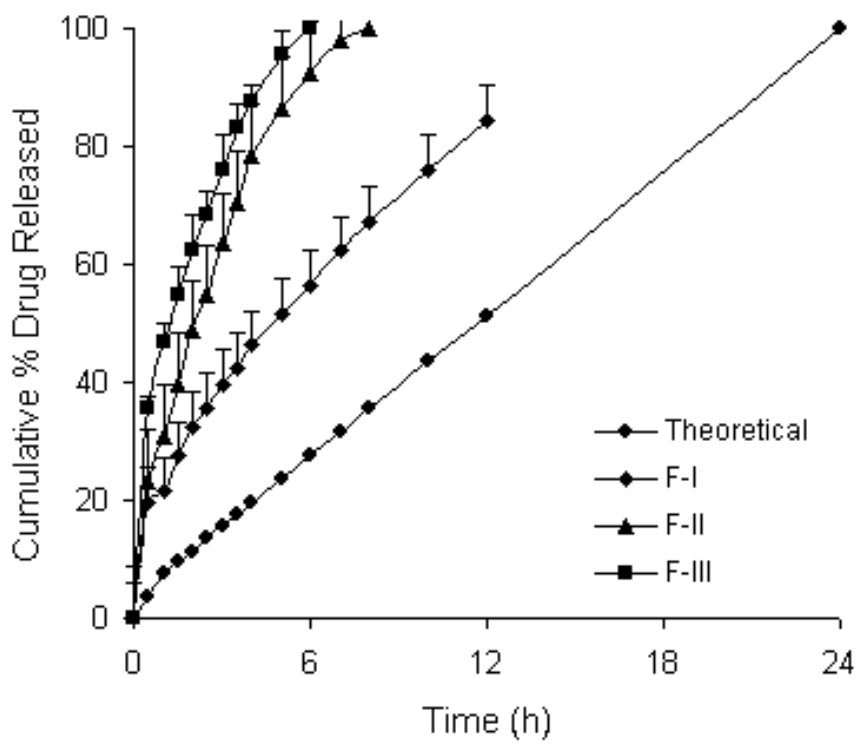

Figure 1. The in vitro release profiles of nicorandil from F-I (HPMC, $320 \mathrm{mg}$ ), F-II (CMC, $320 \mathrm{mg}$ ), and F-III (sodium alginate, $320 \mathrm{mg}$ ) formulations. Each point represents mean $\pm \mathrm{SE} ; \mathrm{n}=3$.

\section{DISCUSSION}

Nicorandil is a potent potassium channel opener and coronary vasodilator presently considered an important drug for the treatment of hypertension and angina pectoris. In the case of cardiovascular diseases, successful treatment can be achieved only by maintaining blood pressure at a normal physiological level, and for this a constant and uniform supply of drug is desired. Multiple dose administration at intervals of 6 to 8 hours is difficult for a hypertensive patient or a patient with angina, which can lead to patient noncompliance. Nicorandil with all evident advantages proved to be a suitable candidate for development of a controlled-release dosage form. In the present study, HPMC, CMC, and sodium alginate, which are commonly used in hydrophilic matrix drug delivery systems, have been employed to formulate sustained-release tablets of nicorandil.

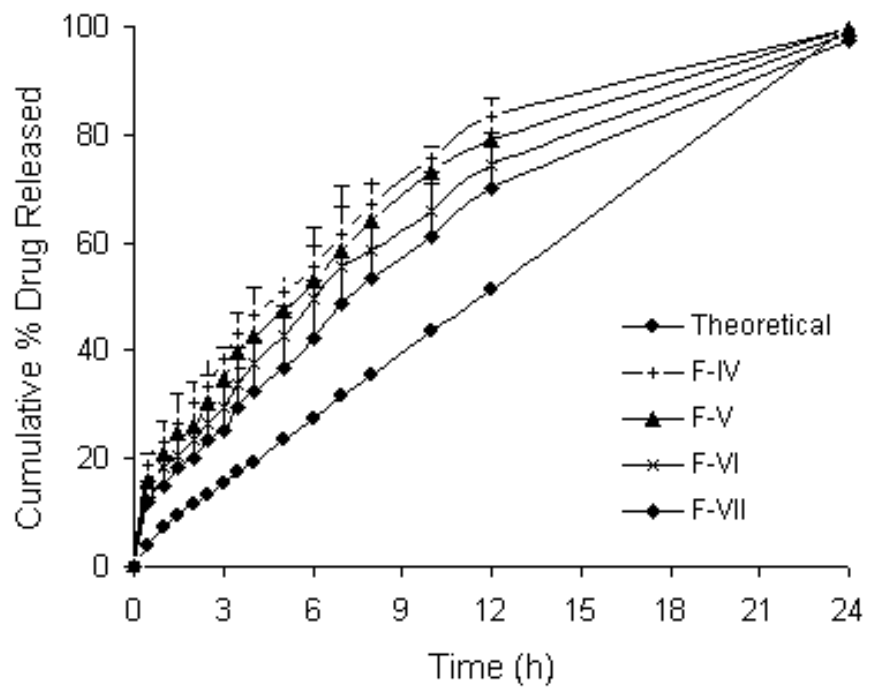

Figure 2. The in vitro release profiles of nicorandil from FIV (HPMC, 320 mg; PVP, 20 mg), F-V (HPMC, 320 mg; ERL $20 \mathrm{mg}$ ), F-VI (HPMC, $320 \mathrm{mg}$; ERS, $8 \mathrm{mg}$ ), and F-VII (HPMC, $320 \mathrm{mg}$; EC, $4 \mathrm{mg}$ ) formulations. Each point represents mean $\pm \mathrm{SE} ; \mathrm{n}=3$. 


\section{AAPS PharmSciTech 2003; 4 (4) Article 61 (http://www.aapspharmscitech.org).}

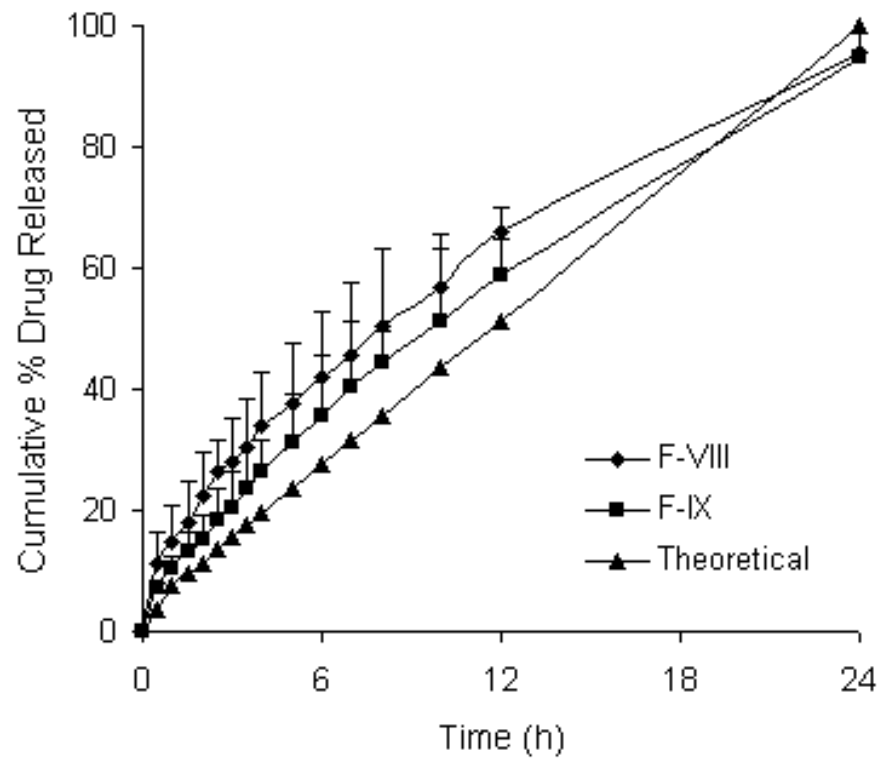

Figure 3. The in vitro release profiles of nicorandil from FVIII (HPMC, $320 \mathrm{mg}$; ERS, $16 \mathrm{mg}$ ) and F-IX (HPMC, 320 $\mathrm{mg}$; EC, $8 \mathrm{mg}$ ) formulations. Each point represents mean \pm $\mathrm{SE} ; \mathrm{n}=3$.

The granules for tablet preparation were prepared according to the formula given in Table 1. Granulation is the key process in the production of many dosage forms involving the controlled release of a drug from coated or matrix-type particles. A granule is an aggregation of component particles that is held together by the presence of bonds of finite strength. Physical properties of granules such as specific surface area, shape, hardness, surface characteristics, and size can significantly affect the rate of dissolution of drugs contained in a heterogeneous formulation. ${ }^{13}$ The granules of different formulations were evaluated for angle of repose, LBD, TBD, compressibility index, total porosity, and drug content (Table 2). The results of angle of repose $(<30)$ indicate good flow properties of the granules. ${ }^{7,8}$ This was further supported by lower compressibility index values (Table 2). Generally, compressibility index values up to $15 \%$ result in good to excellent flow properties. ${ }^{7}$ Bulk densities of granules prepared by using ethanol alone as a granulating agent (F-I, F-II, and F-III) were found to be quite higher than those of other granules. This may be due to the presence of more fines in the granules, as ethanol alone could not provide sufficient binding to the granules. Granule density, porosity, and hardness are often interrelated properties. In addition, granule density may influence compressibility, tablet porosity, dissolution, and other properties. The percentage porosity values of the granules ranged from $26.92 \%$ to $37.61 \%$, indicating that the packing of the granules may range from close to loose packing and also further confirming that the particles are not of greatly different sizes. Gen- erally, a percentage porosity value below $26 \%$ shows that the particles in the powders are of greatly different sizes and a value greater than $48 \%$ shows that particles in the powder are in the form of aggregates or flocculates. ${ }^{8}$ The drug content in the weighed amount of granules of all formulations was found to be uniform. All these results indicate that the granules possessed satisfactory flow properties, compressibility, and drug content.

The tablets of different formulations were subjected to various evaluation tests, such as thickness, diameter, uniformity of weight, drug content, hardness, friability, and in vitro dissolution. All the formulations showed uniform thickness. In a weight variation test, the pharmacopoeial limit for the percentage deviation for tablets of more than $250 \mathrm{mg}$ is $\pm 5 \%$. The average percentage deviation of all tablet formulations was found to be within the above limit, and hence all formulations passed the test for uniformity of weight as per official requirements. ${ }^{9}$ Good uniformity in drug content was found among different batches of the tablets, and the percentage of drug content was more than $95 \%$. The formulation F-IX showed a comparatively high hardness value of $4.9 \mathrm{~kg} / \mathrm{cm}^{2}$. This could be due to the presence of more EC, which is generally responsible for more hardness of the tablet. The low hardness value observed with formulation F-II may be due to the presence of sodium CMC, which generally decreases the hardness of tablets. ${ }^{14}$ Tablet hardness is not an absolute indicator of strength. ${ }^{13}$ Another measure of a tablet's strength is friability. Conventional compressed tablets that lose less than $1 \%$ of their weight are generally considered acceptable. In the present study, the percentage friability for all the formulations was below $1 \%$, indicating that the friability is within the prescribed limits. ${ }^{13}$ All the tablet formulations showed acceptable pharmacotechnical properties and complied with the in-house specifications for weight variation, drug content, hardness, and friability.

The in vitro drug release characteristics were studied in simulated gastric and intestinal fluids for a period of 24 hours using USP XXIII dissolution apparatus 2. The theoretical release profile calculation is important to evaluate the formulation with respect to release rates and to ascertain whether it releases the drug in a predetermined manner. ${ }^{15}$ According to the theoretical release pattern, a once-daily nicorandil sustained-release formulation should release 5.92 $\mathrm{mg}$ in 1 hour and $3.21 \mathrm{mg}$ per hour up to 24 hours.

The results of dissolution studies indicated that F-I, F-II, and F-III released $32.55 \%, 48.75 \%$, and $62.55 \%$ of nicorandil at the end of 2 hours; and $84.53 \%, 100 \%$, and $100 \%$ of drug at the end of 12 hours, 8 hours, and 6 hours, respectively (Figure 1). Among these formulations, the release rate was increased in the following polymer order: sodium alginate $>$ $\mathrm{CMC}>\mathrm{HPMC}$. These polymers have been well known to retard the drug release by swelling in aqueous media. ${ }^{16}$ So- 


\section{AAPS PharmSciTech 2003; 4 (4) Article 61 (http://www.aapspharmscitech.org).}

dium alginate and $\mathrm{CMC}$ released the drug at a faster rate than did HPMC at the same drug-to-polymer ratio. A polymer's ability to retard the drug release rate is related to its viscosity. Sodium alginate, CMC, and HPMC exhibited viscosity values of $250 \pm 50,2500 \pm 25$, and $3000 \pm 50 \mathrm{cps}$ $(2 \% \mathrm{wt} / \mathrm{vol})$, respectively. These results are in accordance with the earlier reported viscosity values for these polymers. ${ }^{14}$ The high dissolution rate observed with sodium alginate could be due to its low swellability, indicated by lower viscosity values compared to other two polymers. Although CMC and HPMC had similar viscosity values, the release rate was higher with $\mathrm{CMC}$, which could be due to the disintegrating property of CMC along with swellability. ${ }^{17,18}$ However, processing factors including wetting on granulation, particle size, and hardness also affect the release rate of drug from tablets.

Initially, tablets were prepared with a drug-to-polymer ratio of 1:1 and ethanol as a granulating agent. But these tablets released $100 \%$ of nicorandil within 4 hours. In an attempt to prolong the release of drug, the concentration of polymer was increased. The tablets prepared with drug-to-polymer ratios of $1: 2$ and 1:3 and ethanol as granulating agent also released $100 \%$ of drug within 2 to 12 hours (results not shown). Finally, tablets with drug-to-polymer ratio of 1:4 were prepared (F-I, F-II, and F-III). Among the polymers tested, HPMC could retard the release only up to 24 hours, and hence it was selected for further formulation development. HPMC is mixed alkyl hydroxyalkyl cellulose ether containing methoxyl and hydroxypropyl groups. The hydration rate of HPMC depends on the nature of these substituents. Specifically, the hydration rate of HPMC increases with an increase in the hydroxypropyl content. The solubility of HPMC is $\mathrm{pH}$ independent. ${ }^{19}$ In the present study, HPMC K4M was used because it forms a strong viscous gel on contact with aqueous media, which may be useful in controlled delivery of highly water-soluble drugs.

F-I to F-III showed burst release of nicorandil in the initial hours, which is probably due to faster dissolution of the highly water-soluble drug from the core and its diffusion out of the matrix forming the pores for the entry of solvent molecules. A suitable sustained-release formulation should release the required amount of drug in the initial hour, followed by slow release. Hence, initial burst release and high deviations in the release profile from the theoretical release pattern demonstrated the need for further development to find a suitable formulation to mimic the theoretical pattern. The formulation F-I, which exhibited the slowest dissolution profile of the initial series, was modified using different granulating agents, such as PVP (10\% wt/vol, F-IV), ERL $(10 \% \mathrm{wt} / \mathrm{vol}, \mathrm{F}-\mathrm{V})$, ERS (4\% wt/vol, F-VI), and EC (2\% $\mathrm{wt} / \mathrm{vol}, \mathrm{F}-\mathrm{VII})$, to control the drug release in the initial hours, besides making the formulation release a high cumulative amount of drug at the end of 24 hours. The formulations FIV, F-V, F-VI, and F-VII released 30.46\%, 26.13\%, $23.63 \%$, and $20.15 \%$ of the drug at the end of 2 hours and $99.50 \%, 99.36 \%, 98.92 \%$, and $97.61 \%$ of the drug at the end of 24 hours, respectively (Figure 2). Among these, the release rate was increased in the following order: PVP $(10 \%)>\operatorname{ERL}(10 \%)>\operatorname{ERS}(4 \%)>\operatorname{EC~}(2 \%)$, indicating that as the hydrophilicity of the polymer was reduced, the release rate was also reduced. These formulations also showed a high release in the initial hours. However, among these formulations, F-VI and F-VII were selected for further development because they showed comparatively less deviation from the theoretical release profile.

In the further formulation development process, F-VI and FVII were modified by increasing the concentrations of ERS and EC to $8 \% \mathrm{wt} / \mathrm{vol}(\mathrm{F}-\mathrm{VIII})$ and $4 \% \mathrm{wt} / \mathrm{vol}$ (F-IX), respectively. The tablets F-VIII and F-IX released $22.54 \%$ and $15.35 \%$ of the drug at the end of 2 hours, respectively (Figure 3). Furthermore, from 3 to 24 hours, the tablets slowly released the drug, and at the end of 24 hours the drug release was $95.58 \%$ and $94.68 \%$ from F-VIII and F-IX, respectively. Both these formulations can be considered successful since they showed little deviation from the theoretical release pattern throughout the dissolution study period. Incorporation of a high concentration of ERS and EC controlled the drug release in a better manner, which could be attributed to the decreased penetration of the solvent molecules in the presence of hydrophobic polymer, leading to decreased diffusion of the drug from the matrix. At the end of 2 hours, F-IX (granulated with EC 4\% wt/vol) released $15.35 \%$ of the drug, which is very much closer to the theoretical release value and much less than that of F-VIII $(22.54 \%)$. From a commercial point of view, EC is more economical than ERS. Hence, F-IX is the most successful and cost-effective formulation among the matrix tablets developed in the present study.

To know the mechanism of drug release from these formulations, the data were treated according to first-order (log cumulative percentage of drug remaining vs time), Higuchi's ${ }^{20}$ (cumulative percentage of drug released vs square root of time), and Korsmeyer et al's ${ }^{21}$ (log cumulative percentage of drug released vs log time) equations along with zero order (cumulative amount of drug released vs time) pattern. As clearly indicated in Figure 1, the formulations did not follow a zero-order release pattern. The release rate kinetic data for all the other equations can be seen in Table 4. When the data were plotted according to the first-order equation, the formulations showed a fair linearity, with regression values between 0.9358 and 0.9957 . Release of the drug from a matrix tablet containing hydrophilic polymers generally involves factors of diffusion. Diffusion is related to transport of drug from the dosage 
AAPS PharmSciTech 2003; 4 (4) Article 61 (http://www.aapspharmscitech.org).

Table 4. Kinetic Values Obtained From Different Plots of Formulations, F-I to F-IX

\begin{tabular}{|c|c|c|c|c|}
\hline \multirow{2}{*}{ Tablets } & \multirow{2}{*}{$\begin{array}{c}\text { First-Order Plots* } \\
\begin{array}{c}\text { Regression Coefficient } \\
\left(\mathbf{R}^{2}\right)\end{array}\end{array}$} & \multirow{2}{*}{$\begin{array}{c}\text { Higuchi's Plots }^{\dagger} \\
\begin{array}{c}\text { Regression Coefficient } \\
\left(\mathbf{R}^{2}\right)\end{array}\end{array}$} & \multicolumn{2}{|c|}{ Korsmeyer et al's Plots } \\
\hline & & & Slope (n) & $\begin{array}{c}\text { Regression Coefficient } \\
\left(\mathbf{R}^{2}\right)\end{array}$ \\
\hline F-I & 0.9811 & 0.9964 & 0.5045 & 0.9928 \\
\hline F-II & 0.9732 & 0.9967 & 0.5886 & 0.9856 \\
\hline F-III & 0.9827 & 0.9934 & 0.4447 & 0.9948 \\
\hline F-IV & 0.9883 & 0.9944 & 0.5399 & 0.9868 \\
\hline $\mathrm{F}-\mathrm{V}$ & 0.9942 & 0.9821 & 0.5312 & 0.9688 \\
\hline F-VI & 0.9957 & 0.9872 & 0.5842 & 0.9872 \\
\hline F-VII & 0.9897 & 0.9731 & 0.6291 & 0.9908 \\
\hline F-VIII & 0.9467 & 0.9922 & 0.5890 & 0.9981 \\
\hline F-IX & 0.9358 & 0.9707 & 0.7180 & 0.9985 \\
\hline
\end{tabular}

*First-order equation, $\log \mathrm{C}=\log \mathrm{C}_{\mathrm{o}}-\mathrm{K}_{\mathrm{t}} / 2.303$.

"Higuchi's equation, $\mathrm{Q}=\mathrm{Kt}^{1 / 2}$.

"Koresmeyer et al's equation, $\mathrm{M}_{\mathrm{t}} / \mathrm{M}_{\alpha}=\mathrm{Kt}^{\mathrm{n}}$.

matrix into the in vitro study fluid depending on the concentration. As gradient varies, the drug is released, and the distance for diffusion increases. This could explain why the drug diffuses at a comparatively slower rate as the distance for diffusion increases, which is referred as square-root kinetics or Higuchi's kinetics. ${ }^{21}$ In our experiments, the in vitro release profiles of drug from all the formulations could be best expressed by Higuchi's equation, as the plots showed high linearity ( $\mathrm{R}^{2}: 0.9707$ to 0.9967$)$. To confirm the diffusion mechanism, the data were fit into Korsmeyer et al's equation. The formulations F-I to F-VIII showed good linearity $\left(\mathrm{R}^{2}: 0.9856\right.$ to 0.9981$)$, with slope $(n)$ values ranging from 0.4447 to 0.6291 , indicating that diffusion is the dominant mechanism of drug release with these formulations. When plotted according to Korsmeyer et al's equation, formulation F-IX also showed high linearity $\left(\mathrm{R}^{2}\right.$ : $0.9985)$, with a comparatively high slope $(n)$ value of 0.7180 . This $n$ value, however, appears to indicate a coupling of diffusion and erosion mechanisms - so-called anomalous diffusion. The relative complexity of this formulation and its components may indicate that the drug release is controlled by more than one process. Similar results were observed by Fassihi and Ritschel with matrix tablets of theophylline containing EC; they considered the $n$ value of about 0.7 to be indicative of an anomalous release mechanism. ${ }^{22}$ Hence, diffusion coupled with erosion may be the mechanism for the drug release from F-IX.

\section{CONCLUSION}

The hydrophilic matrix of HPMC alone could not control the nicorandil release effectively for 24 hours. It is evident from the results that a matrix tablet prepared with HPMC and a granulating agent of a hydrophobic polymer (EC, 4\% $\mathrm{wt} / \mathrm{vol}$ ) is a better system for once-daily sustained release of a highly water-soluble drug like nicorandil. Formulations FI to F-VIII exhibited diffusion-dominated drug release, whereas the mechanism of drug release from F-IX was diffusion coupled with erosion.

\section{REFERENCES}

1. Frydman MA, Chapelle P, Diekmann H. Pharmacokinetics of nicorandil. Am J Cardiol. 1989;20:25J-33J.

2. Leonetti G, Fruscio M, Gradnik R, Chianca R, Bolla GB, Prandi P, Zanchetti A. Nicorandil, a new vasodilator drug, in patients with essential hypertension. J Hypertens. 1989;7:S292-S293.

3. Camm AJ, Maltz MB. A controlled single-dose study of the efficacy, dose response and duration of action of nicorandil in angina pectoris. $A m J$ Cardiol. 1989;20(63):61J-65J.

4. Lordi GN. Sustained release dosage forms. In: Lachman L, Liberman HA, Kanig JL, eds. The Theory and Practice of Industrial Pharmacy. Mumbai, India: Varghese Publishing House; 1987:430-456.

5. Cooper J, Gunn C. Powder flow and compaction. In: Carter SJ, eds. Tutorial Pharmacy. New Delhi, India: CBS Publishers and Distributors; 1986:211-233.

6. Shah D, Shah Y, Rampradhan M. Development and evaluation of controlled release diltiazem hydrochloride microparticles using cross-linked poly(vinyl alcohol). Drug Dev Ind Pharm. 1997;23(6):567-574.

7. Aulton ME, Wells TI. Pharmaceutics: The Science of Dosage Form Design. London, England: Churchill Livingstone; 1988. 


\section{AAPS PharmSciTech 2003; 4 (4) Article 61 (http://www.aapspharmscitech.org).}

8. Martin A. Micromeritics. In: Martin A, ed. Physical Pharmacy. Baltimore, MD: Lippincott Williams \& Wilkins; 2001:423-454.

9. Pharmacopoeia of India. New Delhi: Ministry of Health and Family Welfare, Government of India, Controller of Publications; 1996.

10. Rawlins EA. Bentley's Text Book of Pharmaceutics. London, England: Cassell and Collier MacMillan; 1977.

11. Andersson KE. Clinical pharmacology of potassium channel openers. Pharmacol Toxicol. 1992;70:244-254.

12. Frampton N. Review of nicorandil and pharmacology and therapeutic efficacy in angina. Drugs. 1992;44:625-655.

13. Banker GS, Anderson LR. Tablets. In: Lachman L, Liberman HA, Kanig JL, eds. The Theory and Practice of Industrial Pharmacy. Mumbai, India: Varghese Publishing House; 1987:293-345.

14. Kibbe HA. Hand Book of Pharmaceutical Excipients. London, England: American Pharmaceutical Association, Pharmaceutical Press; 2000.

15. Mutalik S, Hiremath D. Formulation and evaluation of chitosan matrix tablets of nifedipine. The Eastern Pharmacist. 2000;2:109-111.
16. Michailova V, Titeva S, Kotsilkova R, Krusteva E, Minkov E. Water uptake and relaxation processes in mixed unlimited swelling hydro gels. Int J Pharm. 2000;209:45-56.

17. Khan KA, Rhodes CT. Evaluation of different viscosity grades of sodium carboxy methylcellulose as tablet disintegrants. Pharm Acta Helv. 1975;50:99-102.

18. Shah NH, Lazarus JH, Jarwoski CL. Carboxy methylcellulose: Effect of degree of polymerization and substitution on tablet disintegration and dissolution. J Pharm Sci. 1981;70 (6):611-613.

19. Hogan JE. Hydroxypropyl methylcellulose sustained release technology. Drug Dev Ind Pharm. 1989;15(27):975-999.

20. Higuchi T. Mechanism of sustained action medication. Theoretical analysis of rate release of solid drugs dispersed in solid matrices. $J$ Pharm Sci. 1963;52:1145-1149.

21. Korsmeyer RW, Gurny R, Peppas NA. Mechanisms of solute release from porous hydrophilic polymers. Int J Pharm. 1983;15:25-35.

22. Fassihi RA, Ritschel WA. Multiple layer, direct compression controlled release system: In vitro and in vivo evaluation. J Pharm Sci. 1993;82:750-754. 